\title{
An Intercultural Comparative Study on the Impact of Harmony and Chivalry on $\mathrm{Cu}$-ju and Modern Football
}

\author{
Hanyu Zheng \\ School of Foreign Language, Southwest Petroleum University, Chengdu, Sichuan, China
}

\begin{abstract}
As the representative culture of China and England, harmony in Confucianism and chivalry permeate all aspects of society. From a transcultural perspective, the paper analyzes the impact of the two cultures on the development process of Cu-ju and modern football respectively, further showing the differences of the two cultures and revealing their hidden influences on social outlook.
\end{abstract}

Keywords: $\mathrm{Cu}$-ju, Modern football, Harmony, Chivalry.

\section{Introduction}

Football, as the world's most comprehensive sport, its development and change in each stage always win worldwide attention. When it comes to the origin of football, what must be mentioned are the Chinese cu-ju and modern football originated from England.

In the development of cu-ju and modern football, it can be found that, harmony and chivalry have deeply influenced their development, making them show different characteristics in various aspects. Therefore, this paper analyzes the impact of the two cultures on the development process of cu-ju and modern football by introducing the cultural connotations of harmony and chivalry from a cross-cultural perspective, and compares them to summarize the similarities and differences in the development of the two sports under the influence of the two cultures, as well as to reveal the hidden influence of cultures on social life and outlook.

\section{Harmony in Confucianism}

Harmony has always been the pursuit of Chinese society since ancient times, and many scholars in the pre-Qin period have made their own interpretations concerning harmony, while the systematical idea of harmony, actually, was proposed and carried forward by Confucianism. The emergence of the thought of harmony should be attributed to the background at that time. During the Spring and Autumn period, the Zhou Dynasty was in a state of turmoil and change. Economically, the well-field system collapsed, and private ownership of land came into being. Politically, the slave society was transforming into a feudal society. The set of etiquette in the Zhou Dynasty was destroyed and the social order was chaotic. Confucius believed that this was a turbulent period of "ceremony disintegration". As a result, he yearned for a society of harmonious state which stressed the moral ethics, hoping to promote a high degree of harmony and unity between people and society. Therefore, the essence of Confucianism is that people, nature and society should be all organically interconnected and be viewed as a whole when people consider and deal with problems. The harmony pursued by Confucianism is the harmony between man and society, within man himself, between man and man, and between man and nature.

\subsection{Harmony is the Ultimate Pursuit of Social Governance.}

In the relationship of human beings and society, the harmony emphasized by Confucius is that human beings should devote to build a harmonious society with good trust and friendship. Human beings should find their own positions in the society. Meanwhile, their words and behaviors should consist with the rules of the society.

The emperors of ancient China always attached great importance to social governance and hoped to build a well-ordered society. Therefore, various political thoughts were put forward to manage the country. That "harmony is most precious" (以和为贵) came from the Analects of Confucius compiled by the disciples of Confucius. In this book, Confucius advocates that "in practicing the social institutions, it is harmony that is prized." During the Western Zhou Dynasty, the set of etiquette prevailed, and it established the norms for ritual institutions and social behaviors and set the hierarchy to shape people's thoughts and behaviors to pursue a state of "harmony".

Under the framework of the etiquette, the social hierarchy was strict. During the Spring and Autumn Period, Confucius proposed that if sons would behave filially, fathers paternally, emperors royally and subjects loyally, the whole society would be harmonious, emphasizing that people should find their own position and abide by code of conduct. Later, Confucians continued to develop this theory. In the Western Han Dynasty, the theory, "Three Cardinal Principles" was officially mentioned in Luxuriant Gems of the Spring and Autumn Annals written by Dong Zhongshu, namely "ruler guides subject, father guides son and husband guides wife" (Yan Hongliang and Bramwell, 2008:976). The three cardinal principles emphasized a kind of social master-slave relationship, that is, a subject must be faithful to the emperor and obey the instructions of him. A child must keep in mind that he should be filial, respect and obey his parents, not defying their teachings. The wife should also be faithful to husband, and the remarriage after her husband's death was not advocated. Confucianism held a belief that through this way, the society could run on an orderly track, ethics and morality could be maintained. 
The set of etiquette for social governance treated harmony and order as its core value, in its development process, made contributions to the establishment of harmonious society. In practice, the ultimate goal of this system was to maintain a stable social order by defining the code of conduct between people and people under a definite hierarchy.

\subsection{Harmony is the Goal of Shaping Personality}

Confucianism attaches great importance to the self-cultivation of people and devotes to establish a moral standard for individuals and a norm for the social life. Confucius put forward several principles and virtues such as loyalty, filial piety, sincerity, respect, love, benevolence and righteousness, morality and so on to encourage people to cultivate them, which promoted the self-cultivation of human nature. Later, the Confucius started to expound the concept of "gentleman" (君子) from a perspective of morality, which set all good qualities into one image, advocating people from all classes should take "gentleman" as an ideal example and treat him as a permanent pursuit. Confucius believes that a gentleman has three virtues: benevolence, knowledge and courage. In addition, for the gentleman with these three virtues, more important thing is to behave in an impartial and moderate manner. Under the influence of the Chinese culture of more than two thousand years, the spirit of the gentleman has become the part of our national character and ideal personality, forming an important part of connotation of Chinese culture.

In addition, "the doctrine of the mean" is another important content of Confucian harmonious thoughts for self-cultivation, which means that people should keep an impartial, tolerant and peaceful mind. It is believed that people should cultivate their way of thinking and behavioral habits and adopt an appropriate method to understand and deal with things, and pursue harmony and justice. What it emphasizes is that human's words and deeds should promote a harmonious balance between people and society. People should have a kind and tolerant mind to control their emotions and avoid overly sorrows or joy.

\subsection{Harmony is the Principle for Interpersonal Relationships}

In terms of interpersonal relations, the concept of harmony is reflected more incisively and vividly. As for human nature, Confucianism hopes to foster the character, like the sage, pursuing the nobleness and perfection of personality. What's more, Confucianism advocates people to help, care and support each other, and at the same time, it advises rulers to resort to the ritual system to maintain the harmonious relationships among people. Therefore, an ideal state that people respect and understand each other in social interactions is the pursuit of Confucianism, and harmony is the core principle that everyone should follow.

"Treat others as you want to be treated" (己所不欲勿施于人) is another essence of thought of harmony. Confucius considered it as an important criterion to maintain a harmonious relationship between people. In the process of getting along with other people, at first, one must be strictly with himself. If he does not want to do or bear something, he must do not force others to do that or impose such behaviors on others. Actually, this is to say that a person must keep a broad mind to stand on others' shoes to deal with problems. One should not to be overly self-centered but consider himself as a chain of social interaction to assume his responsibility, making his words and deeds promote interpersonal harmony.

\subsection{Harmony is the Inevitable Requirement for the Relationship between Man and Nature}

In terms of the relationship between man and nature, Confucianism advocates the idea of "heaven and man are united as one" (天人合一) and emphasizes that human beings should understand nature, respect nature, protect nature, and conform to the natural development rule. They are not allowed to change the law of nature in an arbitrary way. During the spring and autumn period, self-sufficient agricultural economy still took a great share. The people still lived a life of tying their belts to the land, relying on the weather for harvest. At that time, agricultural activities were small-scale, characterized by manpower and low productivity. Therefore, ancient farmers must respect the law of nature, plant and cultivate crops according to the seasons, and try their best to come up with solutions to adapt to the change of weather. In addition, it could be seen from images such as "god of land" and "god of valley" that people at that time strove for peaceful coexistence with nature.

\section{Impact on $\mathrm{Cu}-\mathrm{ju}$}

To a large extent, the development process of cu-ju is infiltrated with Confucian cultural quintessence. In the aspects of social governance, human self-cultivation, interpersonal relationship and the relationship between man and nature, harmony in Confucianism has took on different cultural appearance, and these connotations have deeply influenced the development of cu-ju.

At first, harmony emphasizes the development of the etiquette, advocating that people should put themselves in the right position in the society and follow the three cardinal principles. Therefore, the people must obey the will and the order of the ruler. In practice, the development form and trend of cu-ju activities, to a large extent, is influenced by personal will of the ancient ruler. The first emperor of the Han Dynasty, Liubang, in order to make his father who was addicted in cu-ju feel satisfied, specially built a place for his father to enjoy the fun of cu-ju with friends and promoted this sport among the whole state. On the contrary, in Ming dynasty, the emperor Zhu Yuanzhang, when seeing some generals and soldiers ignore the military affairs and indulge themselves in beauties and cu-ju, thought that the negative influences would greatly harm the military power, thus put a ban to keep the military staff from cu-ju activities. The two examples are very typical. The former one demonstrates that cu-ju is greatly promoted due to the promotion of the emperor, therefore, the scope of the activities and the number of participants increases greatly. The latter one shows that, affected by the emperor's prohibition, the social status and degree of participation of cu-ju is greatly curbed. As a result, with the change of the will of the rulers, people's attitude towards the sport has also been adjusted accordingly, thus making the social status of cu-ju in each dynasty go down and up. 
Secondly, thoughts on interpersonal relationship derived from harmony deeply influences the degree of confrontation in cu-ju activities. Actually during this process, Confucianism attached great importance to the enlightenment effect of "poems, calligraphy, rites and music", advocating the virtues of the gentleman in the whole society and the idea that "peace is most precious". Gradually, people started to admire the elegance and nobleness of gentleman and despised the assertive behaviors performed in the physical confrontations. As it was mentioned above, cu-ju was once used as a special training method to enhance the physical fitness of soldiers. In the course of the competition, there existed strong physical confrontations. Till the Tang and Song Dynasties, the confrontation of the cu-ju activities weakened, and the main form of the game was changed to adapt to the form of indirect confrontation, focusing on the complicated tricks or freestyle moves of individuals. Therefore, with the change of dynasties, the emphasis on complicated rule and antagonism gradually weakened and finally cu-ju was mainly played for leisure, encouraging no force and struggle but peaceful coexistence among people. For example, according to the rules at that time, it was forbidden to make aggressive and intentional wounding actions in cu-ju activities, such as "stepping on the person" and "stamping on one's shoulders", etc. It must ensure that the game was held in a peaceful form, prohibiting any dangerous actions and unfriendly behaviors.

Moreover, when it comes to the moral attitude of man, the traditional Chinese culture with Confucianism as its core emphasizes "the doctrine of the mean" (in Chinese, "中庸"), preaching people to establish such an attitude towards life that stands aloof from the worldly fame and vanity, and advocating the mild and friendly behaviors and the harmonious relationship. Therefore, in most cases in the game, it is considered that "stopping at where it is appropriate" was the best state, and players would not over-suppress the opponents and create humiliating scores, for instance, one team scores 20 goals while the other gets zero score. Players should not be overly frustrated or ecstatic about losing or winning, and generally they would accept the results of the game in a peaceful mind.

In addition, in terms of organizations, Qi Yun She (齐云社) was an organization of hobbyists, and the atmosphere in it was very friendly. Professional artists boasting high-level techniques in it would teach other members the standardized moves selflessly and patiently. And the members in it were allowed to hold competitions, but only from the starting point of learning from each other. What's more, as a national cu-ju event, the Shanyue Game (山岳正赛) was only aimed at judging the technical level of the artist, not in the name of the fame and fortune. Influenced by such a social atmosphere, cu-ju can be popularized as a kind of entertainment, because if it develops into a highly competitive and antagonistic sport, it seems not to conform to the ethical norms and ideal personality of Confucianism.

Harmony in Confucianism advocates that people should respect and follow the rule of nature, conforming to the ideology of "heaven and man are united as one". Similarly, any activity should also be carried out in accordance with the nature. Qi Yun She put forward some principles for those who participate in associations to abide by. For example, the principles of "Do not kick when there are strong winds" and "Do not kick when one gets drunk" were also the direct reflections of this ideology. It was in line with the harmonious ideology that people should not reverse but follow the law of nature, pay attention to self-cultivation and protect personal safety. Man and nature are intrinsically connected, so all human behaviors should follow the law of nature and achieve harmony between man and nature.

\section{Characteristics of Chivalry}

The earliest meaning of "chivalry" is the equestrian, which derives from the image of a medieval knight, who usually owns a fast and strong horse, a sharp weapon, and a sweetheart who is in conformity with the romantic image in legends.

Born in Europe in the middle ages, knight appeared as a special class, and later grew to represent a title of honor for showing social status. At that time, when the society was in turmoil and chaos, focusing on the need of war, the king and nobles needed a large number of brave and skillful soldiers to fight for the country. In the beginning, the system of compulsory military service for free men was adopted. However, later, due to the gradual development of feudal private ownership of land in Western Europe, the phenomenon of land annexation seemed more serious, and the number of free men decreased. Most of them were confined to land and lords. When Charlie Matt took as a court chief in Merovingian Dynasty, in order to expand his vassal, he put forward to carry out the "fiefdoms" system to grant the land to the lords with honor as a fief (Zhang Yiwei, 2018). This system greatly helped to raise the combat capacity of the country. And through the fief system, it gradually formed a kind of feudal hierarchy in that times: the king, a duke, marquis, earl, viscount or baron, knight. The feudal Lord who obtained the fief was awarded the title of knight and gained a certain social status. Gradually, he began to cultivate his subordinates to become knights to fight for him. England had also implemented this system since William I. Knights had to serve in the Lord's army, went to war when it was in need. It was an honor and a belief for knights to be rewarded with a fief. Therefore, in this group, there must be a value and ideological standard as the guide, so that all knights could admire a thought, which is the reason for the emergence of chivalry.

The knight class attaches great importance to personal glory and is willing to sacrifice for it, which contains some positive factors of the martial spirit in the middle ages and represents the noble character of the knight. The virtues of chivalry include humility, honor, sacrifice, bravery, mercy, honesty, spirit and justice.

To become a knight, one must be polite and graceful in his daily life, be courteous to women, to the old, to the weak, and to all who bear no malignant will. To be a knight, one must regard honor as a banner, fight for it, and dare to make sacrifices for the glory. To become a knight, bravery is one's necessary character. In the face of difficulties and dangers, one must be fearless to defend his territory and interests instead of retreating. To become a knight, one must have a heart of compassion for the weak. It's kind of him to protect 
them and fight for their justice. To become a knight, one must be honest and trustworthy and reject any form of cheating. As the knight declaration said, a knight must be loyal to the soul of himself. To become a knight, one must have a steely heart filled with strong spiritual strengths, and use it as a beacon or a shield to withstand everything evil around. A more precious virtue for knight is to pursue justice with persistence, take the lead for others, and abide by the rules and regulations. This is the chivalry that all the medieval European knights believed in and carried forward. It has been developed and has deeply influenced the national character and social style of Europe in the course of thousand years' development. Chivalry could be said to be an advanced culture, even beyond its times. The pursuit of justice, integrity and other moral characters sets a great example for modern values.

\section{Impact on Modern Football}

The spirit of chivalry has deeply influenced the national character of people in England and even the whole Western Europe. This outstanding spirit has continued to develop and penetrate into all aspects of the social life. Modern football is a sport full of competitiveness. The spirit of it is a candle that makes chivalry shimmering in the contemporary era. It can be said that chivalry makes this sport full of romanticism and idealism.

Generally speaking, football players have a strong desire to win in each match. From the first second of the game to the end of injury time, they are fighting for the victory of the team, which is the continuation of chivalry and the pursuit of honor. Knight class since formulated, has had a tournament play, and the martial atmosphere is popular in the group. As knighthood became more appealing and successful, there grew a need for more training and opportunities for knights to acquire fame. Tournaments provided the perfect scenario for both of these to happen (Matos-Ayala, 2013:4). At first, the tournament play was just a game between two knights, but in the long-term development, the scale of the knights' tournament became bigger, the form of game was more complicated and the regulation stricter, finally becoming a game many audiences appreciate. The purpose of knights in the competition is not just to improve themselves, but more to gain the glory of victory, the audience's applause, and the higher social status. It's the same with modern football players.

In modern times, the national team of England has three lions as its emblem. And the lion is the symbol of courage, loyalty and nobility. It is like a flag, always encouraging football players to fight bravely like knights to strive for the honor for their motherland, to be full of sense of honor, to have a noble sportsmanship and to fight in an upright manner. The characters of the English always remind themselves not to become a hooligan who plays dirty tricks on the football field. It is their belief that players should subdue others by actual ability but not dirty tricks or violence. Therefore, except to the reasonable physical confrontations within the scope of rules, they would not deliberately harm the opponent for the sake of victory.

Meanwhile, the modern football game takes on the feature of intensity and competitivity, and the premier league is the league with the highest intensity, the strongest confrontation and the fastest rhythm among the five major leagues. These aspects clearly reflect the inheritance of chivalry in England. In the middle ages, a person, who had excellent physical quality and strong psychological quality and went through layers of strict selection and training, can become a knight in the end. This is also the same requirement for modern athletes, only by perseveringly honing their skills and techniques, so that they can adapt to the intensity of the fierce match and the fast pace of the game, thus winning their own place on the court.

In addition, one of the most important characteristics of chivalry reflected on modern football is "loyalty", which means the players must be loyal to their teams. Thus, when a player plays for a team and his contract expires, he could transfer to other club, at this time, there is an unwritten rule that one should not transfer to the bitter rival of his previous team. For example, it is almost impossible for players from Manchester United to transfer to Liverpool. If a player did this, he would be denounced as a traitor.

Finally, it can be seen that modern football, in its process of development, constantly pays attention to the update and modification of the rules, making it be more suitable with the need of modern football and emphasizing fairness more. English football not only adopts the principle of "neutrality" in the referees' selection but also introduces the "VAR" (Video Assistant Refree). In modern times, if there would be a football match between the England and American, in order to avoid bias, the referee cannot be chosen from the two countries but from a neutral country to ensure fairness. Situations in modern matches change rapidly, some foul movements often occur in a blink of an eye. Sometimes, it is difficult for the referees to make accurate and reasonable judgments due to some interference factors. In view of many wrong judgments that have occurred in the past caused negative impacts in the society, now the VAR technology is introduced. When the referee is unable to affirm his decision, he can resort to watching the playback recorded by the video assistant referee on the sidelines to remake penalty. The chivalry in pursuit of fairness and justice has deeply influenced the national characters of people in England, which in turn have deeply influenced the development of football, making the game keep pace with the times. Therefore, it has become the world's largest sport.

\section{Comparison of the Impacts}

In comparison, it can be noticed that in the specific development of ancient Chinese cu-ju and modern football, there are similarities and differences, which is due to the influence of their own cultures.

The similarities between harmony and chivalry lie in the fact that they both pay attention to the improvement of people's self-cultivation and lead people to reflect on their own morals. Harmony requires people to learn the virtues of the gentleman, such as courtesy and kindness. Chivalry requires people, from the bottom of their hearts, to be sympathetic with the weak and the kind. Therefore, the influence of the two characteristics on sports, cu-ju and football, is that they both stress a kind of sportsmanship in the process of the game and require the players of both sides to respect each other. The 
slogans "friendship first, competition second" and "opponents on the field, friends off the field" are the reflections of the similarities of the two spirits. Both cultures intend to create a harmonious and fair social atmosphere, and both seek fairness and justice in the results of competitions. Therefore, they constantly revise the rules in the development process to ensure the fairness of competitions.

However, one of the biggest differences is embodied in the harmony of Confucianism, which emphasizes "the doctrine of the mean" and "heaven and man are united as one". It believes that people should pursue a peaceful psychological attitude and be indifferent to fame and vanity. On this basis, it is difficult to form a highly-competitive social atmosphere. However, the western chivalry, prevailing in the period when the bourgeoisie was booming, emphasizes the subjective initiative of human beings and believes that through efforts, people could change their destinies and affirm their values in the society. Therefore, in the process of match, it often can be seen that even the last minute of injury time, players can still run tirelessly, which is because they believe that until the last moment, the game still has the possibility to reverse the game. Thus in many games, the final hit often appears before the whistle is blown. One of the most famous examples is the Manchester United coach, Sir Alex Ferguson. When he was the coach, he instilled the spirit of keeping struggling and never giving up until the last moment to the players. Therefore, in the past, it was often seen that Manchester United reverse the disadvantage position in the final minutes of the game. These last moments which was later called as "Ferguson time" often make audiences feel touched deeply. It is the chivalry that influences the national character. On the field, the player is like a knight, fighting for the glory of the home team.

\section{Conclusion}

This paper finds that the most representative cultures reflected on cu-ju and modern football are harmony and chivalry, which are the essences of Chinese and English cultures and have largely shaped the national characters of the two countries. By analyzing and comparing the influences of different cultures on the development of sports, it can be concluded that: harmony in Confucianism has deeply influenced the development forms of cu-ju. In the form of competition, confrontation gradually weakened, and harmonious relationship is emphasized in the match. Entertainment becomes the main function and the players pay more attention to the freestyle moves and techniques. In contrast, with the infiltration of chivalry, modern football emphasizes confrontation and regards competitiveness as its main function. Players highlight the cultivation of technical and tactical abilities. Meanwhile, the awareness of rules is enhanced and the pursuit of fairness is constantly being pursued in the modern football.

\section{References}

[1] Matos-Ayala, Stephanie. Chivalry in Literature and Practice: A Study of the Medieval Code of Arms Before and After the Arthurian Legends and its Practice in the Battlefield [D]. Pennsylvania: Indiana University of Pennsylvania M.A. thesis, 2013.
[2] Yan, H. L. \& Bill Bramwell. Cultural Tourism, Ceremony and the State in China [J]. Annals of Tourism Research, 2008 (4): 969-989.

[3] Dong Zhongshu. Luxuriant Gems of the Spring and Autumn Annals [M]. Zhengzhou: Zhongzhou Ancient Books Publishing House, 2010.

[4] Zhang Yiwei. Study on British cultural identity from a historical and cultural perspective $[\mathrm{J}]$. Modern Communication, 2018(4): 89-90.

[5] Ren Zhenpeng, Zhou Xiaodong. The Decline of Chinese $\mathrm{Cu}-\mathrm{Ju}$ and the Beginning of Modern Football: Ruled by Rites and Rule of Law[J]. Sports Science Research, 2016(2): 8-11.

[6] Huang Jinkui, Wu Shengyi. The In-depth Reflection on the Decline of $\mathrm{Cu}$-ju Game in Ancient China and the Emergence of Modern Football Game in Great Britain[J]. Journal of Capital University of Physical Education and Sports, 2013(4): 320-324, 329.

[7] Confucius. The Analects[M]. Beijing: Chinese Textile Publishing House, 2015.

[8] Yue Changzhi, Ma Guoqing. Chinese $\mathrm{Cu}-\mathrm{ju}[\mathrm{M}]$. Jinan: Shandong Friendship Publishing House, 2013.

[9] Zhang Mengjie. The Evolution of $\mathrm{Cu}-\mathrm{ju}$ in Ancient China[J]. Sports Culture Guide, 2015(3): 162-164, 194.

\section{Author Profile}

Hanyu Zheng received the B.A. Degree in English major from Southwest Petroleum University in 2019 and will graduate from SWPU in June, 2022 in Translation major and receive M.TI. Degree. 